Share Tendering Strategies and the Success of Hostile Takeover Bids Author(s): David Hirshleifer and Sheridan Titman

Source: The Journal of Political Economy, Vol. 98, No. 2 (Apr., 1990), pp. 295-324

Published by: The University of Chicago Press

Stable URL: http://www.jstor.org/stable/2937667

Accessed: 18/02/2011 17:37

Your use of the JSTOR archive indicates your acceptance of JSTOR's Terms and Conditions of Use, available at http://www.jstor.org/page/info/about/policies/terms.jsp. JSTOR's Terms and Conditions of Use provides, in part, that unless you have obtained prior permission, you may not download an entire issue of a journal or multiple copies of articles, and you may use content in the JSTOR archive only for your personal, non-commercial use.

Please contact the publisher regarding any further use of this work. Publisher contact information may be obtained at http://www.jstor.org/action/showPublisher?publisherCode=ucpress.

Each copy of any part of a JSTOR transmission must contain the same copyright notice that appears on the screen or printed page of such transmission.

JSTOR is a not-for-profit service that helps scholars, researchers, and students discover, use, and build upon a wide range of content in a trusted digital archive. We use information technology and tools to increase productivity and facilitate new forms of scholarship. For more information about JSTOR, please contact support@jstor.org. 


\title{
Share Tendering Strategies and the Success of Hostile Takeover Bids
}

\section{David Hirshleifer and Sheridan Titman}

University of California, Los Angeles

\begin{abstract}
This paper presents a model of tender offers in which the bid perfectly reveals the bidder's private information about the size of the value improvement that can be generated by a takeover. We argue that bidders with greater improvements will offer higher premia to ensure that sufficient shares are tendered to obtain control. The model relates announcement date returns and takeover success or failure to the amount bid, the initial shareholdings of the bidder, the number of shares the bidder attempts to purchase, the dilution of minority shareholders, and managerial opposition. We show that managerial defensive measures will sometimes increase the probability of the offer's success, either by raising the incentive to bid high or by decreasing the asymmetry of information about the improvement.
\end{abstract}

When a hostile bidder makes a tender offer for a widely held firm, target shareholders must evaluate competing claims to decide whether or not to tender their shares. Bidders typically accuse the incumbent management of mismanaging the firm and claim that they are offering a fair price for its shares that reflects the higher value of the target under their direction. Management, on the other hand,

We especially thank the referee of this Journal, Milton Harris, and Robert Vishny for extremely helpful comments. We also thank Michael Brennan, Peter Carr, Julian Franks, Ron Giammarino, David Levine, Ivan Png, Eric Rasmusen, Avanidhar Subrahmanyam, Brett Trueman, and participants at seminars at University of British Columbia, University of California at Berkeley and Los Angeles, Carnegie-Mellon University, Columbia University, Northwestern University, Stanford University, Vanderbilt University, University of Washington, and the Symposium on Financial Contracting at Indiana University for helpful comments. 
often accuses the bidder ("raider") of trying to buy shares on the cheap, offering insufficient compensation given the true value of the firm's assets.

The target shareholders' assessment of these claims generally cannot be known in advance. Furthermore, shareholders may have specific attributes such as liquidity or tax considerations that affect their tendering decisions. For these reasons, the outcome of an offer is generally uncertain. This is evidenced by the observed negative price reactions of target shares on announcements of the failure of an offer (Bradley, Desai, and Kim 1983; Samuelson and Rosenthal 1986; Ruback 1988) and by the positive reactions of the bidder's stock price to success and negative reactions to failure (Bradley 1980).

Grossman and Hart (1980) were the first to explain that, because of a free-rider problem, target shareholders may rationally turn down bids that offer substantial premia over the current market price. They argued that if atomistic shareholders of the target firm are able to share fully in the improvements brought about by a successful takeover without tendering their own shares, they will not accept an offer unless the price equals or exceeds the posttakeover value of the shares. They further argued that if takeovers are to be profitable, bidders must be able to dilute the posttakeover value of the shares that are not tendered. The threat of dilution induces target shareholders to tender at a price that allows the bidder to cover his costs associated with the takeover.

Shleifer and Vishny (1986) pointed out that takeovers may still be profitably undertaken without dilution if the bidder had accumulated a large fraction of the target firm's shares prior to publicly announcing the offer. Although these large shareholders cannot on average profit from the additional shares they purchase, they realize gains on the shares they owned prior to the tender offer that are at least sufficient to cover their costs. An important innovation in the Shleifer and Vishny paper is the introduction of an informational asymmetry between the purchaser, who knows the posttakeover value of the target firm, and the target shareholders, who do not. Given this asymmetry, target shareholders cannot be certain whether it is in their interest to tender their shares.

Although the Grossman and Hart and Shleifer and Vishny papers provide important intuition about why shareholders might view some offers as inadequate, in their analyses no observed bid ever fails. With the reservation prices of the target shareholders known with certainty, a given offer either is high enough to succeed or else will fail with certainty. Since bids that fail with certainty are obviously unprofitable, the bids in these models will be made only at the minimum acceptable price. 
This paper provides a model in which observed tender offers sometimes do fail. The argument above indicates that for offers to fail, the bidder must be uncertain about the prices at which shareholders will tender. This type of uncertainty will arise if shareholders have some personal costs and benefits of tendering (e.g., transaction costs and tax or liquidity considerations) that are not known by the bidder. Even if these costs are zero, bidders may still be uncertain about the outcome of an offer if shareholders follow mixed strategies (i.e., randomize) when they are indifferent about whether or not to tender their shares. We show that similar results can be obtained with either setting. However, since the mixed-strategy equilibrium is more tractable, we relegate the development of the model with random tendering costs to Appendix B. ${ }^{1}$

A fundamental property of the bidding game we describe is that shareholders are more likely to accept high bids than low ones. In consequence, bidders with low potential gains from the takeover can bid low to separate themselves credibly from high-gain bidders. A high-gain bidder will not find it in his interest to offer as low a bid because rejection is more costly to him. The greater willingness of low-value bidders to make low offers leads to an equilibrium in which the offer perfectly reveals the information of the bidder, with the bid exactly equaling the posttakeover value of the shares.

A positive relation between the bid premium and the probability of offer success is also a feature of recent takeover models with multiple bidders (e.g., Giammarino and Heinkel 1986; Fishman 1988; Hirshleifer and Png 1990). ${ }^{2}$ These papers differ from those of Grossman and Hart and of Shleifer and Vishny in assuming that offers are made to management, rather than directly to shareholders. This assumption is more relevant for friendly merger bids, in which the target behaves as a unit, than for hostile tender offers, which are subject to a freerider problem among shareholders. ${ }^{3}$

This paper also examines scenarios that allow for a free-rider problem among target shareholders and yet also allow managers to affect

\footnotetext{
${ }^{1}$ Harsanyi (1973) has shown that in some games, as private shocks to player-specific costs and benefits become arbitrarily small, the behavior of the players can be described by a mixed-strategy equilibrium.

${ }^{2}$ The model is also similar to the recent work by Giammarino and Lewis (1988) that analyzes the decision of a firm to issue new shares to finance a known investment project. In their separating equilibrium, the higher-valued firm offers shares at a higher price, taking the risk that the issue will be rejected. Because their cost of failure is higher, lower-valued firms do not mimic this action.

${ }^{3}$ Berkovitch and Khanna (1988) examine the choice of friendly and hostile takeover methods in a single model. Morck, Shleifer, and Vishny (1988) have provided evidence that tender offers are used in hostile takeovers to discipline poorly performing management, while merger bids are more likely to be associated with friendly takeovers.
} 
the success or failure of bids by resisting offers. We show that the managerial defensive measures affect the success of takeovers not only by affecting the strategies of bidders but also by affecting how shareholders interpret the bid. In particular, some defensive actions can potentially increase the likelihood of the bid's success, either by raising the incentive to bid high or by decreasing the asymmetry of information about the improvement. As a result, defensive measures can potentially improve welfare as well as increase the value of the target firm. However, defensive strategies can also be designed to entrench management and thereby reduce welfare.

\section{Offer Prices as Signals of Posttakeover Value}

\section{A. The Basic Model}

This section presents the model in its simplest form. We assume that, with the exception of one potential acquirer who owns the fraction $\alpha$ of the firm's shares, shareholders of the target firm are atomistic and hence view the success of the tender offer as independent of their individual tendering decisions. These holdings are determined exogenously and are unrelated to the posttakeover value of the firm. If the potential acquirer can successfully purchase the fraction $0.5-\alpha$ of the firm's shares, he can gain control of the firm and improve its value by the amount $z$ per share. This amount, which is bounded above by $\bar{z}$, is known only to the potential acquirer. ${ }^{4}$ To simplify the notation we assume that the firm's value under the incumbent management is zero. If the potential acquirer attempts to take over the firm, a conditional tender offer is made for a controlling portion of the firm's shares. In other words, the bidder makes no purchase unless the number of shares tendered is at least as large as the number he has chosen to bid for; otherwise the offer fails. ${ }^{5}$ We assume that the po-

\footnotetext{
${ }^{4}$ The model may be expanded so as to make $\bar{z}$ endogenous. Suppose that the range of possible positive values of $z$ is unbounded. We assume that the manager maximizes his own expected wealth and possesses initial shareholdings $\gamma$ in the firm. He obtains perquisites with value $Q$ from control of the firm, but in deciding whether to accept or reject a friendly merger bid (rather than a tender offer), he balances this against the profit he obtains from selling his shares, $x^{m} \gamma$, and allowing the merger to take place, where $x^{m}$ is the premium per share in a merger bid. This implies a critical value for the improvement, called $\bar{z}$, above which the bidder prefers to make a friendly merger bid, which will be accepted, rather than a hostile tender offer.

${ }^{5}$ We have also examined unconditional or "any and all" tender offers. Although the analysis is somewhat more complex, it yields essentially the same substantive results. Currently, a large proportion of tender offers are made unconditionally. However, since these offers can be withdrawn prior to the expiration date if the bidder believes that an insufficient number of shares will be tendered, we think our characterization of conditional offers probably offers a realistic description of unconditional offers as well. See Bagnoli and Lipman (1988) for further analysis of "any and all" tender offers.
} 
tential acquirer gets only one opportunity to bid: if it is rejected, there is no opportunity for later upward revisions. The critical aspect of this assumption is that the bidder's loss from being rejected is increasing with the size of his improvement. At the end of this section, we shall discuss ways in which the assumption of just a single bid can be relaxed. It is assumed that all market participants are risk neutral.

Up to this point, the assumptions are essentially identical to those in Shleifer and Vishny (1986). They imply that shareholders will turn down all bids that are less than the expected posttakeover value of the nontendered shares and accept all bids that exceed this value. Shleifer and Vishny further assume that shareholders always accept bids that make them indifferent. Given this assumption, they show that in equilibrium all bidders make the same bid, and shareholders always tender because the equilibrium bid equals the expected value as assessed by shareholders given that bid. Hence, observed bids never fail.

To construct an alternative equilibrium in which bids sometimes do fail, we begin by describing the problem faced by a bidder. Let $x$ be the amount per share bid, and let $\omega$ be the fraction of the outstanding shares for which he bids. Let $P(x ; \alpha, \omega)$ be the probability that at least $\omega$ shares are tendered to a potential acquirer who bids $x$ and begins with an initial shareholding of $\alpha$ in the target. Let $C$ be the cost of making a bid. Although $C$ is known to the bidder, it need not be known to target shareholders. If more than $\omega$ shares are tendered, the shares are prorated, so that the bidder still pays $x$ per share for $\omega$ shares.

We shall propose an equilibrium in which the potential acquirer, if he chooses to bid, makes an offer for exactly $\omega=0.5-\alpha$ shares, independent of the level of $z$. If a bid is made, the level of the bid is chosen to maximize his expected gain,

$$
\max _{x}[\alpha z+(z-x) \omega] P(x ; \alpha, \omega)-C .
$$

If we assume that $P(x ; \alpha, \omega)$ is twice differentiable with respect to the amount of the bid, the sufficient first- and second-order conditions with respect to $x$ are

$$
P^{\prime}[\alpha z+(z-x) \omega]-P \omega=0
$$

and

$$
P^{\prime \prime}[\alpha z+(z-x) \omega]-2 P^{\prime} \omega<0 .
$$

We assume that for each $z$ there exists an $x$ such that (2) and (3) obtain to ensure an interior optimum. ${ }^{6}$ Then the following proposition holds (all proofs are in App. A).

\footnotetext{
${ }^{6}$ A rather mild condition on the probability schedule that ensures this is that $P(0)=$
} 
Proposition 1 . If the probability of success $P(x ; \alpha, \omega)$ is strictly increasing in the level of the bid, then the optimal bid $x(z)$ is a strictly increasing function of the improvement $z$.

The intuition is fairly straightforward. Bidders who can realize higher improvements are willing to bid higher to increase the probability that the offer succeeds because they have more to gain from a successful takeover. Proposition 1 suggests that the pooling equilibrium of Shleifer and Vishny may be sensitive to the assumptions of their model that permit the probability schedule to make a discontinuous jump from zero to one. For example, if we perturb the model by making $y$, the information about $z$ possessed by the target shareholders, imperfectly known to the bidder, then the shareholders' tendering decisions cannot be foreseen with certainty by the bidder. The Shleifer-Vishny equilibrium is based on shareholders' inference about $z, E(z \mid y, x)$, not rising too rapidly with $x$, so that if $y$ is a known constant, any bid greater than or equal to $E(z \mid y, x)$ is accepted with certainty. But with $y$ stochastic, there will be a probability that $x$ exceeds or is smaller than $E(z \mid \tilde{y}, x)$, so that the offer may succeed or fail. Hence, the probability that the offer succeeds, instead of a step function, will be smoothly increasing in the bid. As proposition 1 demonstrates, a smoothly increasing probability schedule will induce bidders to reveal their levels of improvement through their bids, that is, a separating rather than a pooling outcome. ${ }^{7}$

If bids are to be accepted probabilistically, there must be uncertainty about the prices at which shareholders will tender. Such uncertainty arises in our model as a result of target shareholders' random choice of whether or not to tender their shares when they are indif-

0 and that the percentage rate of increase in probability with the bid is decreasing in the bid:

$$
\frac{\partial}{\partial x}\left[\frac{P^{\prime}(x ; \alpha, \omega)}{P(x ; \alpha, \omega)}\right]<0 .
$$

${ }^{7}$ Even in the original game, the Shleifer and Vishny equilibrium is sensitive to the specification of beliefs. The belief that supports their equilibrium is that all bidders who would profit from an accepted low bid are equally likely to make the error of bidding too low. Under these beliefs, the low bid is below the conditional expected value of the gain from takeover, so shareholders will always reject. This is in contrast to the Banks and Sobel (1987) criterion of universal divinity, which requires that the likelihood of an offequilibrium low bid be assessed to be lower for types for whom such a move is desirable under a more restricted set of responses by shareholders. It should be noted that the pooling equilibrium is not removed by some other well-known refinement concepts, such as the intuitive criterion of Cho and Kreps (1987) and perfect sequential equilibrium of Grossman and Perry (1986). However, we believe that the arguments breaking the equilibrium are intuitively appealing. Since the risk of having a bid rejected is less costly to a low- $z$ bidder than to a high- $z$ bidder, shareholders should infer that low bids are more likely to be associated with low $z$ 's. This tends to promote the acceptance of low bids, so that the pool evaporates. 
ferent, that is, when $x=E(z \mid x)$. If they are indifferent, we follow the convention that the target shareholders' tendering strategies are chosen so that the probability of the offer's success at different levels of the bid supports the proposed equilibrium behavior of the bidders. ${ }^{8}$ The intuitive justification for a mixed-strategy equilibrium is that if the bid makes shareholders very nearly indifferent about whether to tender, then from the bidder's perspective the actions of the shareholders will seem random (see n. 1). In Appendix B, we model this explicitly, assuming that the shareholders' tendering decisions are deterministic functions of characteristics unknown to the bidder. The mixed-strategy model we develop in this section may be viewed as a metaphor for a situation with unknown characteristics of shareholders; it has the advantage of being far more tractable than the model of Appendix B, while yielding the same basic intuitions.

In a mixed-strategy separating equilibrium, the bid must make target shareholders indifferent between tendering and not tendering. This is the case in the proposed equilibrium in which the bid is fully revealing with $x=z$. To demonstrate that such an equilibrium exists and to solve for the probability schedule that supports it, we substitute the inference schedule $\hat{z}(x)=x$ for $z$ into (2) and rewrite the equation in terms of $x$ as

$$
\frac{P^{\prime}}{P}=\frac{\omega}{\alpha x} .
$$

Integrating both sides of (4) over $x$ and rearranging terms yields a schedule that expresses the probability of the tender offer's success as an increasing function of the level of the bid, that is, $P(x ; \alpha, \omega)=k x^{\omega / \alpha}$, where $k$ is a constant of integration. The constant $k$ is determined by noting that shareholders will accept any bid greater than $\bar{z}$ with certainty since they can do no better by retaining their shares. It follows that $P(\bar{z})$ must equal one (otherwise, the bidder would raise the bid by one cent), so the probability schedule is

$$
P(x ; \alpha, \omega)=\left(\frac{x}{\bar{z}}\right)^{\omega / \alpha} .
$$

This applies when the expected net profit from bidding,

$$
\alpha x P(x ; \alpha, \omega)-C=\alpha x^{(\omega+\alpha) / \alpha} \bar{z}^{-(\omega / \alpha)}-C,
$$

is positive. The expected profit is increasing in $x$, so there exists a

\footnotetext{
${ }^{8}$ For a given bid $x$, shareholders do not need to coordinate their actions to generate a probability of $P(x)$ of offer success. With a large finite number of shareholders, any arbitrary probability of success may be achieved when shareholders select independent tendering probabilities close to $1 / 2$. For an analysis of how stochastic outcomes can result from a continuum of random variables, see Judd (1985).
} 
critical value $z^{c}$ below which no offer is made, determined by equating the expected profit to zero. There is also a minimum value of $\alpha$ consistent with profitable bidding, $\alpha^{*}=C / \bar{z} \cdot{ }^{9}$ The preceding results can be summarized in the following proposition.

Proposition 2. In the tender offer game described above, a mixedstrategy Bayesian equilibrium exists with the following properties: (1) The bid equals $z$ (and hence perfectly reveals the bidder's private information) for all $z \geq z^{c}$, where $z^{c}=(C / \alpha)^{\alpha /(\omega+\alpha)}(\bar{z})^{\omega /(\omega+\alpha)}$. For $z<z^{c}$, no bid is made. (2) The tender offer will be successful with probability $P(x ; \alpha, \omega)=(x / \bar{z})^{\omega / \alpha}, x \in\left[z^{c}, \bar{z}\right]$. (3) The bidder will offer to buy $\omega=$ $0.5-\alpha$ shares, the minimum needed to obtain control.

In this analysis a bidder with a high $z$ is induced to submit a high bid by the dependence on the bid of the likelihood that the tender offer will succeed. ${ }^{10}$ Since a bidder with a low $z$ gains less from a successful offer, he is less willing than a high- $z$ bidder to increase his bid. Similarly, because of a higher opportunity cost associated with the failure of an offer, a bidder with high $z$ is not motivated to bid low. Finally, there is no incentive to bid for more shares than the minimum needed to gain control because, by (5), bidding for more shares reduces the probability of success. ${ }^{11}$

\section{B. Empirical Implications of the Basic Model}

The following points summarize a number of empirical implications of proposition 2.

\footnotetext{
${ }^{9}$ For example, if the cost of bidding is 5 percent of the maximum possible improvement, the minimum initial shareholding needed to make bidding profitable is 5 percent of the target. Poulsen and Jarrell (1986) report a range of initial holdings of bidders varying from 0 percent to nearly 50 percent. The minimum $\alpha$ needed will be smaller and can easily be zero if dilution of target shareholders is possible (as in Sec. $\mathrm{I} C$ ).

${ }^{10}$ If shareholders do not know the size of $C$, every sensible bid (i.e., $x \in(0, \bar{z}]$ ) is viewed by shareholders as possible in the equilibrium. Hence, if the number of shares bid for $\omega$ is taken as given, the separating equilibrium is robust to all the standard refinements (e.g., intuitive criterion, divinity, and perfect sequential equilibrium), for the simple reason that it does not require shareholders to draw inferences from out-ofequilibrium moves.

${ }^{11}$ Although we have confirmed that the mixed tendering strategy supports a Bayesian equilibrium, one may wonder whether the belief revisions are credible in the face of deviants who bid for a greater number of shares, $\omega>0.5-\alpha$. For example, consider the alternative belief that those who did so had low values of $z<x$. Then their bids would always be accepted. This high acceptance rate would encourage bids for more than $0.5-\alpha$ shares. However, this deviant belief is not consistent because if a bid of $x<$ $\bar{z}$ were always accepted, then those with $z>x$ would also find it profitable to bid $x$. On intuitive grounds, it is not plausible that bidding for more shares is a signal of low $z<x$. It is when the bidder intends to bid below his value, $z>x$, that he profits from his share purchases and has something to gain by buying a greater number of shares. So the proposed belief, which rules out using high share purchases as a way of signaling low size of improvements, seems reasonable.
} 
IMPLICATION 1. The probability of an offer's success increases with the bid premium and with the initial holdings of the bidder in the target, and it is decreasing in the number of shares required to obtain control.

The intuition is that when, for example, a supermajority provision forces the bidder to make an offer for more shares, the marginal savings from underbidding are greater, so a steeper slope of the probability schedule is required to deter the highest type of bidder with $z=\bar{z}$ from underbidding. The effect of $\alpha$ on the probability of success arises because lower $\alpha$ implies relatively lower potential profits from originally owned shares compared with purchased shares, which increases the incentive to underbid. So if the bidder has a smaller initial holding, it takes a larger drop in probability to deter a highvaluation type from underbidding. This is shown in figure 1 , where for the highest possible bid $\bar{x} \equiv \bar{z}, P(\bar{x} ; \alpha, 0.5-\alpha)=1$ for both high

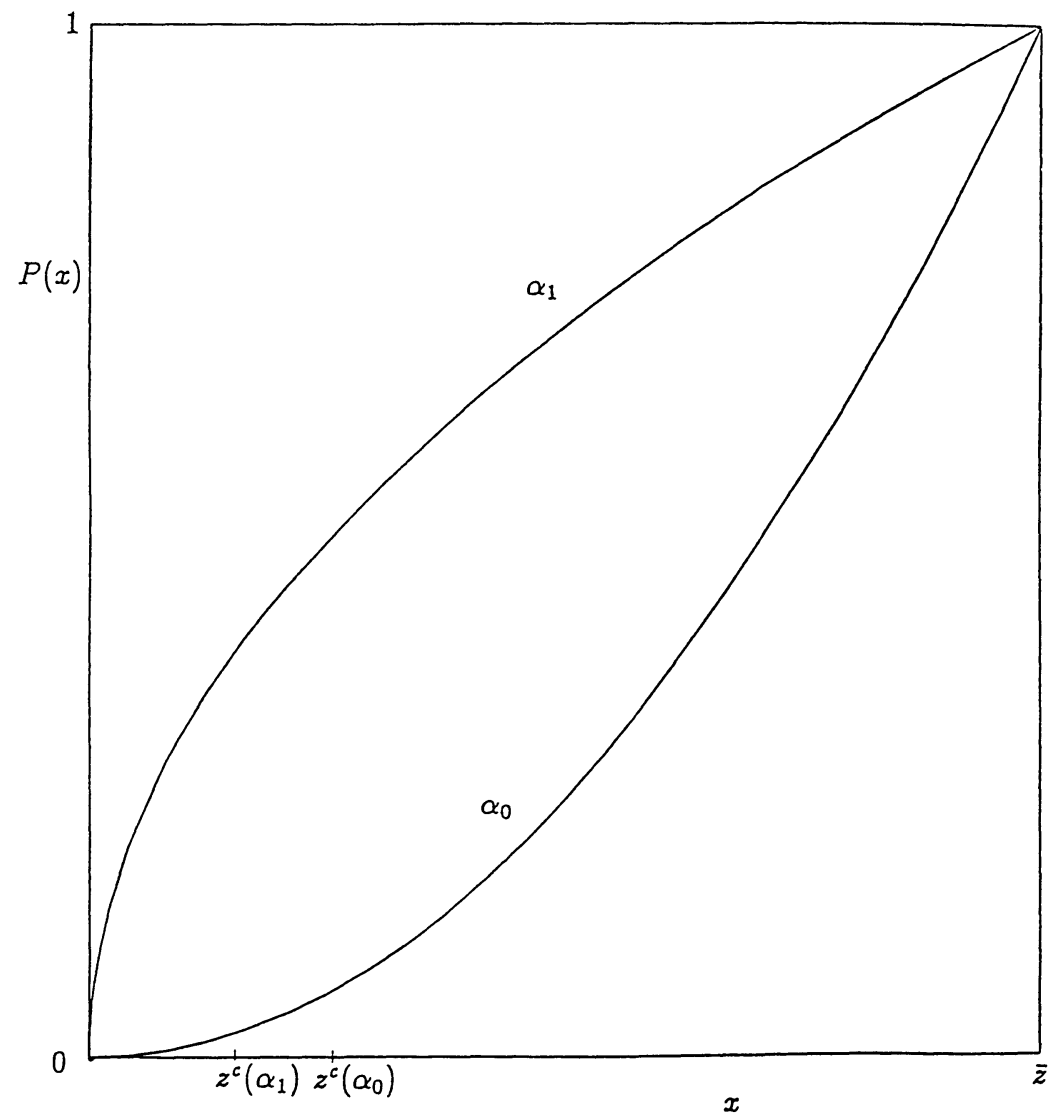

FIG. 1.-Probability of offer success as a function of the level of the bid $\left(\alpha_{1}>\alpha_{0}\right)$ 
and low $\alpha$, so that for lower $\alpha$, the schedule is steeper at the right endpoint. The result that the probability of success rises with the bid premium and with the bidder's initial holdings is consistent with the evidence of Walkling (1985).

IMPLICATION 2. The ratio of the stock price reaction at the announcement of the bid to the bid premium is increasing in both the level of the bid and the initial shareholdings of the bidder, and it is decreasing in the number of shares required to obtain control.

This implication is due to the impact of these parameters on the probability of an offer's success.

It is also of interest to examine the effect of varying parameters on $z^{c}$. This leads to the following prediction.

IMPLICATION 3. The average bid premium declines with the size of the bidder's initial holdings in the target and increases with the number of shares needed to obtain control.

An increase in $\alpha$ raises the expected profit from making an offer by increasing the probability of success and increasing profits in the event the offer succeeds. As a result, increasing $\alpha$ makes it profitable for lower-type bidders to make an offer, so $z^{c}$ and, hence, the average bid decline. ${ }^{12}$ Moreover, with bids more likely to be made and more likely to be successful, the preoffer market price is higher. This is consistent with Walkling and Edmister (1985), who document that the average bid premium over the market price is decreasing in the initial shareholding of the bidder. ${ }^{13}$ Similarly, an increase in the number of shares needed to win control, by reducing the probability of success, causes $z^{c}$ to increase, raising the expected premium. If the number of shares needed for control varies across firms, this is also consistent with the evidence of Walkling and Edmister, who found that a 0-1 variable indicating whether more than $0.5-\alpha$ shares were sought in the bid had a positive impact on average premia.

Implication 4. Activities that reduce the degree of asymmetry of information between bidder and shareholders, such as the payment of solicitation fees to persuade shareholders to tender, are predicted to increase the probability of offer success.

\footnotetext{
${ }^{12}$ Algebraically, the formula for $z^{c}$ in proposition 2 declines as long as $\alpha>C / e \bar{z}$, where $e$ is Euler's constant. This must hold in the relevant range of $z^{c} \leq \bar{z}$, which implies $\alpha \geq C / \bar{z}$.

${ }^{13}$ However, the evidence of Franks and Harris (1988) is only partially supportive. Consistent with the prediction, they find that the premium is lower if the initial shareholding exceeds 30 percent than if it is positive but less than 30 percent. However, the premium is also lower in the third category of zero shareholdings. This is consistent with the hypothesis that offers made without an initial shareholding are made by bidders with a credible threat to dilute target shares, leading to lower bid premia (see Sec. IC).
} 
A reduction in the degree of asymmetry of information, that is, a mean-preserving inward shift in the distribution of $z$ that lowers $\bar{z}$, the maximum possible value of the improvement, will, by proposition 2 , raise the probability of offer success at any given level of the bid. In consequence, the bidder will be motivated to take actions to communicate information about the source of and likely magnitude of the improvement to target shareholders. This could be one function of hiring brokers to solicit shares. Consistent with our analysis, Walkling finds that the payment of solicitation fees does increase the probability of takeover success.

\section{The Solution with Dilution}

Grossman and Hart (1980), in a model with only small shareholders, stress that for tender offers to be profitable some means by which a successful bidder can dilute the value of minority holdings is needed. ${ }^{14}$ Shleifer and Vishny pointed out that if there is a large shareholder, he can profitably initiate a bid without dilution. In this subsection we examine a solution in which the potential bidder has large shareholdings and also has the power to engage in some dilution of minority shareholders.

Suppose that the amount by which minority shares may be diluted contains a fixed component $\delta_{0}$ and a proportional component $\delta_{1}$, where $\delta_{0}$ and $\delta_{1}<1$ are known constants. A dilution by $\delta_{0}+z \delta_{1}$ means that after obtaining control, the bidder can reduce the value per share, so that the posttakeover value of minority shares is $z(1-$ $\left.\delta_{1}\right)-\delta_{0} \cdot{ }^{15}$ Since target shareholders do not know $z$, this assumption implies that they also do not know the posttakeover value of their shares.

In a perfectly revealing equilibrium, shareholders will be just indifferent about whether to tender if they receive a bid they believe to be equal to the posttakeover value,

$$
x=z\left(1-\delta_{1}\right)-\delta_{0} .
$$

\footnotetext{
${ }^{14}$ Dilution refers not just to expropriation of assets of the target, but to sharing some of the gain from the improvement. We therefore view dilution as widely prevalent, and despite the connotation of the word, it need not indicate any malfeasance or predatory behavior on the part of the bidder.

${ }^{15}$ More generally, one might allow $\delta_{0}$ and $\delta_{1}$ to be random. However, this would change the solution radically because the probability needed to persuade a bidder to bid "truthfully" $-x=z\left(1-\delta_{1}\right)-\delta_{0}$-will in general depend separately on the bidder's $z$ and on his $\delta_{1}$; for a given $z\left(1-\delta_{1}\right)-\delta_{0}$, the gains to success are greater for a bidder with higher $z$ since his profit on his own shares is larger. We conjecture that this should lead to a solution in which bidders sometimes overbid and sometimes underbid but in which the bid is equal to $E\left[z\left(1-\delta_{1}\right)-\delta_{0} \mid x\right]$ (to keep the shareholders indifferent).
} 
The probability schedule will depend on $\delta_{0}$ and $\delta_{1}$, but we suppress all arguments except for $x$ and write the probability of success as $P(x)$. The bidder's objective function is then

$$
\max _{x}\left[\alpha z+\omega(z-x)+0.5\left(\delta_{0}+\delta_{1} z\right)\right] P(x) .{ }^{16}
$$

Following steps that parallel the previous section, we may take the first-order condition of the bidder's problem, invert the bidding function (6) to obtain the inference schedule $\hat{z}(x)=\left(x+\delta_{0}\right) /\left(1-\delta_{1}\right)$, and substitute $\hat{z}(x)$ for $z$ in the first-order condition to obtain a differential equation for $P(x)$. Shareholders will always accept the highest possible bid, $\bar{x} \equiv\left(1-\delta_{1}\right) \bar{z}-\delta_{0}$, so $P(\bar{x})=1$. This boundary condition implies the probability schedule

$$
P(x)=\left(\frac{x+\beta_{0} \beta_{1}}{\bar{x}+\beta_{0} \beta_{1}}\right)^{\beta_{1}},
$$

where $\beta_{0} \equiv \delta_{0} / \omega\left(1-\delta_{1}\right)>0$, and $\beta_{1} \equiv \omega\left(1-\delta_{1}\right) /\left[\alpha+\delta_{1}(1-\alpha)\right]>0$. As $x$ is linearly related to $z$, the probability of success is indirectly a function of the improvement $z$,

$$
P^{*}(z)=\left(\frac{z+d}{\bar{z}+d}\right)^{\beta_{1}}
$$

where, by its definition, $\beta_{1}<\omega / \alpha$, and $d=\left(\beta_{0} \beta_{1}-\delta_{0}\right) /\left(1-\delta_{1}\right)>0$. Since the displacements $\beta_{0} \beta_{1}, d>0$ are increasing in $\delta_{0}$ and $\delta_{1}$, while $\beta_{1}$ is decreasing, the probability of success is uniformly higher than it is in the basic model and increases with the amount of dilution.

Profits increase with dilution both directly in (7) and as an indirect result of the increased probability of success. As a result, $z^{c}$ decreases. Dilution therefore raises the probability that a bid will be made, as well as raises the probability of success of an outstanding offer. It remains the case with dilution that higher initial shareholdings $\alpha$ increase the probability of offer success and reduce the critical value $z^{c}$.

The intuition for why the probability of success increases with the amount of dilution $\left(\delta_{0}\right.$ and $\left.\delta_{1}\right)$ is roughly that the effect of being able to dilute is similar to the effect of raising $\alpha$ described in Section IA. Higher dilution increases the cost to underbidding because a given

\footnotetext{
${ }^{16}$ The term $0.5\left(\delta_{0}+\delta_{1} z\right)$ may be interpreted in two ways. Finally, if dilution has no deadweight costs, it reflects the profit to the bidder when he can successfully appropriate resources from the minority shareholders. Alternatively, if dilution is costly, after obtaining a majority of shares from a tender offer, with the value of the improvement revealed, the bidder can make a cleanup offer for the remaining shares, setting the bid in the cleanup offer equal to $z\left(1-\delta_{1}\right)-\delta_{0}$. Since the bidder would profitably dilute the minority were this offer to fail, the remaining shareholders are all willing to tender.
} 
drop in probability reduces the expected gain arising from the term $0.5 \delta_{1} z$ by a greater amount. When $z$ is high, this implies a shallower slope of the probability schedule when $\delta_{1}$ is high. But when $z$ is low, the differential in probabilities between a low- and high- $\delta_{1}$ bidder becomes larger, increasing the benefit for a bidder to underbid if $\delta_{1}$ is high.

The model predicts that dilution threats will be reflected in the "first tier" of the offer, so that minority shareholders do no worse than those who tender. However, in Section II $B 2$ we shall see that when managers take defensive measures, "overbidding" is possible, so that the bid can potentially exceed the postoffer share price.

\section{Costs of Bid Failure}

The preceding model assumes that if target shareholders reject the bid, the bidder will lose the target with certainty and hence will suffer costs that are increasing in the size of his improvement. In reality a bidder who is rejected by shareholders may be able to revise his bid and ultimately succeed. If a first failure were entirely costless, then a low-type bidder would be unable to separate from a high-type bidder on the first bid.

There are a number of reasons why rejection of an initial bid may ultimately result in a failed or at least a less profitable acquisition. For example, the rejection may result in the loss of a window of opportunity, such as a reduction of synergies. Alternatively, failure of the initial bid may give management or labor unions more time to mobilize legal or asset structure defensive activities. If the management response blocks the takeover, it leads to a loss to the bidder that is consistent with the assumptions of the basic model. A failed bid may also give management the opportunity to learn about and take steps to preempt the policies planned by the bidder, increasing the firm's pretakeover stock price and making the takeover unprofitable. If the bidder profits only on his initial stake $(\alpha)$, this could in principle help him as much as an actual acquisition. However, if incumbent management cannot implement the improvements or synergies efficiently, or if (as will normally be the case) the bidder can appropriate some positive fraction of a takeover improvement through dilution, then the attempt to preempt the improvement imposes an opportunity cost on the bidder that increases with the size of the improvement.

Another important consideration is that rejection may give competing bidders time to enter. Again, this would involve a loss of the gains associated with dilution. If we set $\alpha=0$ in the model with dilution, the solution is identical to that of an alternative model in which a 
failed offer always results in the appearance of a competing bidder who can successfully purchase the firm by matching the initial bid. The objective function of the first bidder is then just (7) with $\alpha=0$, and the probability schedule is precisely $(8)$ with $\beta_{1}=\omega\left(1-\delta_{1}\right) / \delta_{1}$. This illustrates simply that a separating equilibrium can be enforced by a cost of failure arising from a competing bidder who appropriates the potential dilution. ${ }^{17}$

\section{Management Defensive Actions}

There has been a great deal of debate about whether managerial defensive measures are in shareholders' interests or whether they are a means of entrenching managers pursuing their own objectives (see, e.g., Easterbrook and Fischel 1981; Gilson 1981; Bebchuk 1982). In the next two subsections we examine three categories of defensive measures: contingent cost defensive strategies, which impose costs on the bidder only in the event that he is successful; pretakeover costs, which are imposed on the bidder prior to the outcome of the offer; and blocking defensive strategies, which increase the likelihood that the bid will be disallowed for legal reasons. Our analysis takes these defensive measures as exogenous and examines their effects on the amount that the bidder offers, the tendering strategies of target shareholders, and the probability of offer success. We show that while some defensive measures reduce shareholder value, others can increase both the amount bid and the probability of the offer's success.

\section{A. Contingent Defensive Costs}

A number of defensive strategies impose costs on the bidder only in the event that a tender offer succeeds. These strategies may redistribute wealth from the successful bidder to the nontendering shareholders; they may impose deadweight costs on the bidder without affecting the value of untendered shares or they may reduce the posttakeover value of the remaining shares as well. These distinctions are important since the type of cost imposed affects both the shareholders' tendering decisions and the bidder's strategy.

The following is a general model that incorporates all three possibilities. As a special case, in Section II $A$ 1, we examine "poison pills," in which the loss to the bidder, should the pill be triggered, is fully redistributed to the remaining target shareholders; in Section II $A 2$, we examine value-reducing measures ("sale of the crown jewels"), in

${ }^{17}$ A competing bidder model in which the initial stake of the first bidder is positive is available from the authors on request. 
which the shareholders who do not tender are also hurt by the defensive measure. ${ }^{18}$

Let $h(z)$ be the cost per share imposed on the shares either originally held or purchased by the bidder should the bid succeed. If the takeover succeeds, the value per minority share is increased by an amount $z+e h(z)$, where $-1 \leq e \leq 1, h(z)>0$, and $h^{\prime}(z) \geq 0$. Here $h(z)$ will generally be increasing in the improvement. For example, in a discriminatory rights offering to all shareholders but the bidder (a poison pill), the rights will be worth more when the firm is worth more. The term $e$ is a redistributive parameter that reflects the fact that the target shareholders may not fully appropriate the costs imposed on bidders.

In a mixed-strategy separating equilibrium, the bidder must bid the value of the target shares should the takeover succeed, inclusive of the redistribution, so that

$$
x=z+e h(z) .
$$

Given the costs imposed on the bidder, his problem is

$$
\max _{x}[\alpha z+(z-x) \omega-0.5 h(z)] P(x) .
$$

If $h$ is linear, that is, $h(z)=a+b z$, where $b<1$, the equilibrium is derived from the first-order condition of $(10)$ by substituting for $z$ using (9) and solving the differential equation for $P(x)$. Imposing the boundary condition of certain success at the highest bid, $P(\bar{x})=P[\bar{z}+$ $e h(\bar{z})]=1$, we obtain

$$
P(x)=\left[\frac{x-(B / A)}{\bar{x}-(B / A)}\right]^{\omega(1+e b) /[\alpha-b(\omega e+0.5)]},
$$

where $A=[\alpha-b(\omega e+0.5)] / \omega(1+e b)$, and $B=[0.5 a(1+e)] / \omega(1+$ $e b)$. Insight into particular forms of managerial defensive measures may be derived by examining special cases of this model. The following subsections examine cases in which $e=-1$ and $1 .{ }^{19}$

\footnotetext{
${ }^{18}$ A sale of valuable assets prior to a bid can still be considered a "contingent" cost, in the sense that the bidder's wealth is reduced by this action more if his offer succeeds than if it fails. Of course, from the target shareholders' point of view, a measure that becomes operative only if the takeover succeeds (such as legislation limiting investment changes by new management) may be very different from a sale of assets that becomes operative regardless of whether a takeover occurs.

${ }^{19}$ The intermediate case of $e=0$ corresponds to defensive measures that, while imposing costs on the bidder in the event of success, do not affect the wealth of the minority target shareholders. This may approximate the effects of charter amendments providing for staggered terms of directors. When a bid succeeds, these amendments may force the bidder to suffer further litigation costs, or the costs of a proxy fight, before implementing his program. In our model, such measures imply a uniform reduction in the probability of offer success.
} 


\section{Poison Pills: Redistributive Defensive Measures}

A poison pill is a defensive measure that redistributes wealth from the bidder to the shareholders who do not participate in the tender offer if the bidder accumulates a sufficient number of shares. Such a redistribution corresponds to $e=1$ in (11), implying that the probability schedule is identical in form to the schedule in the model with dilution, with $\delta_{0}=-a$ and $\delta_{1}=-b$. In other words, poison pills can be viewed as mechanisms that generate negative dilution. In consequence, the poison pill unambiguously reduces the probability of success and increases the bid for a given level of the improvement. Ryngaert (1988) and Malatesta and Walkling (1988) found a negative average stock price reaction to the announcement of poison pills. This is consistent with our model to the extent that the reduction in the probability of takeover outweighs the benefit to shareholders of being able to extract a higher premium.

\section{Value-Reduction Strategies}

We now examine defensive measures that impose costs on the target shareholders as well as the bidder, should the takeover succeed. One such measure is to lobby for legislation that outlaws the investment changes the bidder wishes to make. Other examples are the "scorched earth" or "sale of crown jewels" defensive measures, in which the firm sells off those divisions or assets whose values can be improved.

A value-reducing strategy is reflected in the current model by a negative $e$, so that reductions in bidder wealth are associated with reductions in the improvement in target shareholder wealth; we examine the pure case in which $e=-1$. It should be stressed that we are considering a defensive measure that reduces the size of the improvement from a takeover. The sale, at below the market price, of an asset that cannot be improved by the acquirer or any other measure that reduced firm value without altering the amount by which it could be improved would have no effect on the probability schedule or on the premium $(x)$ offered above the firm's value under current management. When $e=-1$, the reduction in value per share is the same for the bidder and for the nontendering shareholders. This case is equivalent to a reduction in $z$ at all its values. Hence, by (11),

$$
P(x)=\left(\frac{x}{\bar{x}}\right)^{\omega / \alpha},
$$

as in the basic model. Note that since $\bar{x}=\bar{z}-h(\bar{z})<\bar{z}$, the probability of acceptance as a function of the amount bid rises. This is not surprising since a given bid becomes more attractive when compared with a 
reduced value of the improvement. However, the amount bid will also be reduced, so the probability of success of a bidder with a given improvement of $z$ may or may not be reduced. The level of the bid is

$$
x=z-h(z)=-a+(1-b) z,
$$

which when substituted into (12) gives the probability schedule in terms of $z$ of

$$
P^{*}(z)=\left\{\frac{z-[a /(1-b)]}{\bar{z}-[a /(1-b)]}\right\}^{\omega / \alpha} .
$$

A value-reducing defensive strategy can either increase or decrease the severity of the information asymmetry between the bidder and the other target shareholders, depending on the values of $a$ and $b$. A fixed reduction in the size of the improvement, that is, $a>0$ and $b=0$, makes the improvement more uncertain relative to its mean and hence reduces the probability of success as well as the profits in the event of success. Alternatively, with $a=0$ the probability of offer success is unchanged. The prior uncertainty about the improvement relative to its mean is unaffected by such a measure; however, both the level of the bid and the profits of the bidder are reduced. Therefore, such a strategy can deter a potential bidder from attempting the takeover. ${ }^{20}$

Perhaps most interesting, if $a<0$ and $b>0$, the asymmetry of information about the increase in the value of target shares (net of defensive costs) that the takeover will bring about is diminished. ${ }^{21} \mathrm{By}$ (14), it follows that this value-reduction measure increases the probability of offer success. Intuitively, it is asymmetry of information that leads to bid failure, and to the extent that this can be reduced, the frequency of acceptance is raised. ${ }^{22}$

The results of Section IIA can be summarized by the following proposition.

Proposition 3. For poison pills $(e=1)$, the probability of success as

${ }^{20}$ Dann and DeAngelo (1988) examine a number of cases in which targets sell assets for defensive purposes, and they provide evidence that stock prices decline on average.

${ }^{21}$ To illustrate, let $z=\bar{z}_{1}+z_{2}$, where $\bar{z}_{1}$ is an improvement of known value and $z_{2}$ is an improvement whose value is unknown to target shareholders. These may be viewed as two projects that the bidder could undertake. Consider a measure that imposes costs $b^{\prime} z_{2}$ that are proportional to $z_{2}$, so that $h(z)=b^{\prime} z_{2}=b^{\prime}\left(z-\bar{z}_{1}\right)=b^{\prime} z-b^{\prime} \bar{z}_{1}$. Hence, this measure is subsumed by our general framework with $b=b^{\prime}$ and $a=-b^{\prime} \bar{z}_{1}<0$. It is worth noting that in this example, $z \geq \bar{z}_{1}>0$; i.e., the improvement is bounded from zero. Otherwise, the specification would imply that the defensive measure could be value increasing for small $z$, which does not seem plausible.

${ }^{22}$ For similar reasons, a value-increasing strategy such as preemption by the target management of the planned improvement could decrease the probability of success. This corresponds precisely to the fixed reduction in the improvement, $a>0$ and $b=0$, discussed in the paragraph above. 
a function of either the level of the bid or the size of the improvement $(z)$ is lowered. For value-reducing defensive measures $(e=-1)$, the probability of success as a function of the bid is higher than in the basic model without defensive measures; however, the probability of success as a function of the bidder's improvement can be greater, lower, or the same as when there are no defensive measures. A valuereducing defense can either raise, lower, or leave unchanged the probability that an offer will be made.

\section{B. Litigation}

Litigation by incumbent management imposes costs on the bidder and can in some cases directly block a takeover. Any legal costs undergone by the bidder prior to the outcome of the offer are uncontingent in that they are expended even if the bid should later fail. We examine separately the effect on the bidder's strategy of the uncontingent legal costs that are imposed (Sec. II $B 1$ ) and of the possibility of blocking the bid (Sec. II $B 2$ ).

\section{Defensive Costs Imposed prior to the Offer Outcome}

The analysis that follows assumes that the magnitude of defensively imposed costs depends on the amount bid. ${ }^{23}$ In this case, the bidder's objective is

$$
\max _{x}[\alpha z+(z-x) \omega] P(x)-h(x),
$$

where $h(x)$ is the cost imposed on the bidder by the managerial defensive action prior to the offer outcome, $h^{\prime}(x) \leq 0$. Taking the first-order condition of (15) and substituting the condition for a fully revealing equilibrium that $z=x$ gives a linear first-order differential equation for the probability schedule as a function of $x$. The following proposition, which assumes that the model parameters are such that a mixedstrategy equilibrium exists (i.e., $x=z$ ), can be proved by solving this equation subject to the initial condition $P(\bar{z})=1$.

PROPOSITION 4. In the tender offer game with costs imposed by management defensive litigation, when a separating equilibrium exists, (1) the probability of an offer's success in the mixed-strategy

${ }^{23}$ The assumption that the legal cost of the offer is decreasing in the size of the bid arises from the possibility that courts may be more sympathetic to defensive suits if a low price has been offered to shareholders; e.g., the statutes of a number of states give target shareholders appraisal rights. Alternatively, management may not fight high bids as hard as low bids. 
signaling equilibrium is

$$
P(x)=P_{0}(x)\left[1+\int_{\bar{z}}^{x} \frac{h^{\prime}(t)}{\alpha t}\left(\frac{t}{\bar{z}}\right)^{-(\omega / \alpha)} d t\right],
$$

if this quantity is uniformly less than or equal to one, where $P_{0}(x)$ is the probability schedule that applies when $h^{\prime} \equiv 0$, as in the model without target-imposed costs; (2) if $h^{\prime}<0$, defensive measures increase the probability of an offer's success.

To see that part 2 is true, note that the integrand is a negative quantity $\left(h^{\prime}<0\right)$ and the limits indicate a backward interval $(\bar{z} \geq x)$, so $P(x)$ is higher under the new solution than under the old one. This is intuitive: if we start from the endpoint $x=\bar{z}$ and reduce $x$, the probability may fall less and still deter a lower bid since a lower bid would lead to higher litigation costs. So when a litigation strategy is pursued, the probability of takeover success, given that a bid is made, can actually increase!

Litigation by the target can also lead to offers that exceed the magnitude of the improvement, $x>z$. For example, if the manager is able to impose high costs on all bids below $\bar{z}$, some bidders with improvements below $\bar{z}$ increase their bids to $x=\bar{z}$. In consequence, it is possible that imposing costs on bidders may be in the target shareholders' interest for two reasons: first, because this can raise the probability of an offer's success and, second, because it can increase the pressure to make a higher bid. Jarrell (1985) provides evidence that litigation increases the takeover price and, hence, can sometimes be in the interest of target shareholders.

\section{Blocking Defensive Measures}

In addition to imposing a cost on bidders, management opposition may be able to force the bidder to withdraw his offer for legal reasons. Let $T(x)$ equal the probability that $0.5-\alpha$ shares are tendered, and let $U(x)$ equal the probability that the offer is not blocked by the courts. It is assumed that the two sources of failure occur independently. Let $P(x)$ be defined as the overall probability that a bid succeeds,

$$
P(x)=T(x) U(x) .
$$

The objective of the potential acquirer, if he chooses to bid, is still (1), leading as before to the first-order condition (2). Any solution to this differential equation for which $x=z$, consistent with the randomization of shareholders, satisfies

$$
T(x) U(x)=k x^{\omega / \alpha} .
$$


When we solve for $P(x)$, the difference between this problem and that of Section $\mathrm{I} A$ is that, with $T(x) \leq 1$, the additional constraint $P(x) \leq$ $U(x)$ is imposed.

Sometimes the ability to block the bid is not based on the level of the bid (e.g., "antitrust" defensive lawsuits), in which case the blocking probability $U(x)$ is a constant. Then since $P_{0}(\bar{z})=1$, the schedule $P(x)$ is necessarily lower at the right endpoint, as illustrated in figure 2 . The resulting schedule may be determined by applying the initial condition $P(\bar{z})=U$ to (17). This yields the solution

$$
P(x)=\left(\frac{x}{\bar{z}}\right)^{\omega / \alpha} U
$$

A comparison of (18) with (5) illustrates that in this case the blocking defensive measure uniformly reduces the probability of the offer's success. ${ }^{24}$

In other cases, the probability of the success of a legal action is decreasing in the amount of the offer, that is, $U^{\prime}(x) \geq 0 .{ }^{25}$ If in addition $U(x)$ is never below $P_{0}(x)$, then the boundary condition for $P(x)$ in the basic model may be applied to (17) without modification. Hence, the resulting probability schedule is the same as that in the basic model, implying that the direct loss in probability due to defensive action is precisely offset by an increased willingness to tender! Moreover, as the payoffs to the bidder are exactly the same as before, $z^{c}$ also does not change. So the defensive measure will be entirely ineffective in promoting either shareholders' goals or those of an entrenched management. This extreme case illustrates the more general point that shareholders may compensate for blocking measures by increasing their willingness to tender their shares.

The intuition can be seen by imagining that the tendering probabilities of shareholders were unchanged. Then opposition would increase the incentive of a bidder with a given $z$ to bid high to avoid being blocked. A given bid would thus become more attractive to shareholders. The increased willingness of shareholders to tender at a given bid can offset the direct probability-reducing effect of management defensive measures. ${ }^{26}$

\footnotetext{
${ }^{24}$ More generally, if $U(x)<(x / \bar{z})^{\omega / \alpha}$ for any $x \in(0, \bar{z}]$, then the original schedule $P_{0}(x)$ becomes infeasible. The reduction in probability of success imposed by the defensive action is binding because for some $x$, even were shareholders to tender with certainty, the probability of legal success would be less than $P_{0}(x)$. However, the reduction in probability that results could be slight.

${ }^{25}$ This assumption may be justified by arguments similar to those in $\mathrm{n} .23$.

${ }^{26}$ Further insight into the source of the greater willingness to tender arises from the model of App. B. There, defensive measures can give the bidder an incentive to bid higher, and the higher bidding not only makes shareholders less skeptical in their assessments of $z$ but also raises the probability that the excess of $x$ over the assessed $z$ is
} 


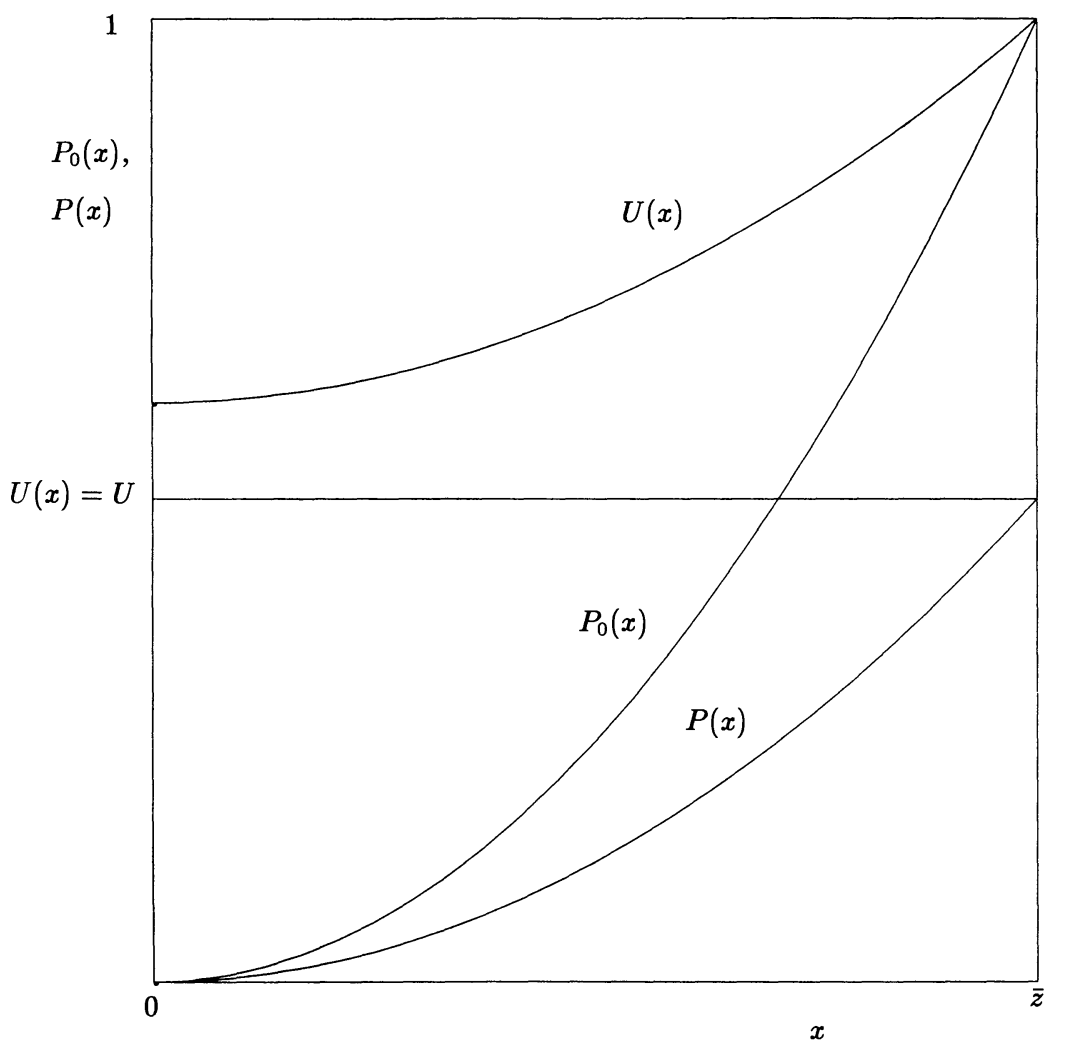

FIG. 2.-Effect of binding defensive measures on the probability of offer success

A sufficiently steep $U(x)$ schedule may lead to overbidding, thereby rendering infeasible a mixed-strategy equilibrium in which bidders offer the true value of the improvement. Under the conditions of proposition 1, bidders still separate because the slope of the $U(x)$ schedule provides an incentive for high- $z$ bidders to make higher offers than low- $z$ bidders. In this case the threat of defensive actions increases the bids and can thus increase the probability of takeover success. Overbidding in some acquisitions is consistent with the evidence of Bradley (1980) that the posttakeover value of those shares not tendered is on average lower than the tender price. ${ }^{27}$

\footnotetext{
large enough to outweigh the costs of tendering. Here, with shareholders just indifferent, the willingness to tender is infinitely elastic with respect to the bid, so the compensation in tendering probabilities is brought about without any rise in the bid at all.

${ }^{27}$ As a simple illustration, suppose that $z$ can take on just two values, $\bar{z}$ and $z$. Suppose that $\mathrm{U}(\bar{z})=1$ but $U(x)=0$ for all $x<\bar{z}$. Then if $\alpha$ and $\underline{z}$ are sufficiently high, it will pay for the lower-value bidder to overbid, $x=\bar{z}$, to be accepted with certainty, since the gain on his own shares will exceed the loss on the shares he purchases.
} 


\section{Welfare and Regulatory Implications}

If we assume that the gain in value from a takeover arises from increasing operating efficiencies rather than expropriation of nonequity shareholders (e.g., bondholders and labor) and if we assume that the direct resource costs of defensive measures are small, then defensive actions that decrease the probability of takeover success decrease welfare. Taking this view, Easterbrook and Fischel (1981) argue for a passivity rule for management on the grounds that extracting a higher bid is merely a redistribution, without net benefits but with the social cost of deterring some potentially profitable synergies. Our model suggests that defensive actions need not reduce social welfare. By forcing the bidder to increase his offer or by reducing the asymmetry of information about the posttakeover value of the target, they can increase the probability of the offer's success.

For example, we show that certain blocking defensive measures as well as cost-imposing litigation strategies force the bidder to raise his bid to a level that leads shareholders to tender with certainty, while some forms of value-reducing strategies also increase the probability of the offer's success by reducing the asymmetry of information. In some cases, the bidder as well as the target is made better off by defensive measures. This will occur when the rise in the probability of success outweighs the higher payment the bidder is forced to make or the loss arising from the reduction in the target's value. In consequence, if the model were extended to consider the decision of bidders to investigate the target, it is possible that defensive measures could lead to a higher overall probability of takeover and higher social welfare.

However, some defensive measures such as poison pills act to reduce dilution and thereby increase the offer price while lowering the probability of offer success. As in Grossman and Hart (1980), our model implies that managers that act in shareholders' interest will take defensive actions to reduce dilution in order to raise the bid above the socially optimal level. Shareholders will support this activity because they bear only part of the social cost associated with the reduced probability of an offer's success and capture a transfer gain from raising the offer price.

This suggests that there may be some role for regulations that limit the use of defensive measures. However, it should be stressed that this argument takes the investment decisions of the target as given. If there exist preoffer investments that a target can make that increase synergies, then to encourage investment it may be socially preferable to allow targets to take actions to capture more of the synergistic benefits. 
Our analysis further suggests that the Williams Act, by facilitating defensive actions, may have promoted overbidding in hostile takeover contests. The risk in bid premia subsequent to the Williams Act described by Jarrell and Bradley (1980) is consistent with this hypothesis. An alternative truncation hypothesis is that a rise in the cost of bidding will raise the average bid premium by deterring profitable takeovers with relatively lower gains. ${ }^{28}$ Overbidding can explain not only the higher premia paid to targets but also the lower abnormal returns to bidders, found by Jarrell and Bradley, after the Williams Act and later state acts. ${ }^{29}$ Malatesta and Thompson (1988) provide evidence that a wealth transfer from bidders to targets (i.e., higher bids) was more important than truncation of the sample in causing the rise in target mean premia and lower abnormal returns to bidders.

The discussion above suggests that regulation that facilitates defensive action can potentially increase welfare, but need not do so. Our analysis indicates that a necessary but not sufficient condition for a defensive strategy to increase welfare is that it benefits target shareholders. A recent paper by Jarrell and Poulsen (1987) indicates that, on average, antitakeover amendments lead to negative target stock price reactions, suggesting that they may, in general, be welfare decreasing. However, the price reaction is not always negative and is on average more positive in those cases in which a large fraction of the firm is held by institutional shareholders, who are presumably better able to block amendments that oppose their interests. This suggests that antitakeover amendments sometimes are in the interest of target shareholders and thus may sometimes improve social welfare.

Our analysis of the desirability of defensive measures may be sensitive to the assumptions about the effects of offer failure. The possible welfare gains arise from forcing up the bid or reducing informational asymmetry, which leads the bidder to succeed with higher probability. In practice, however, a failed first bid can be followed by a revised bid or a competing bid. If the target does not take defensive actions, it is likely to be taken over eventually, either by the initial bidder or, if he fails, by another bidder. This suggests that although defensive actions can increase the probability that an initial bid will succeed, it is unlikely that they will increase the probability that the firm will ultimately be taken over.

If an initial failure leads to less efficient implementation of the

\footnotetext{
${ }^{28}$ Our model is also consistent with the truncation effect. Jarrell and Bradley's discussion combines features of both explanations.

${ }^{29}$ Lower bidder returns could also be due to the increased costs imposed by defensive measures.
} 
improvement, because management either preempts the planned changes inefficiently or finds a white knight who does so, then implications similar to our analysis apply. On the other hand, if an initial failure does not prevent the target from ultimately being acquired by either the first bidder or a competing bidder with either an equal or a greater improvement, then our argument must be modified. In this case, defensive measures that reduce the probability of initial success can be socially beneficial if they give higher-improvement bidders more time to make offers.

\section{Conclusion}

This paper presented a model of tender offers in which the bid perfectly reveals the bidder's private information about the size of the gain that can be generated by a takeover. The magnitude of the tender offer premium affects the probability that a bid succeeds, so that bidders with high-valued improvements who have more to gain from the offer's success make higher bids than those bidders with lower gains. The model provides a number of testable implications relating to the determinants of an offer's success. For example, we have shown that both high initial holdings by the bidder and the possibility of dilution of minority shareholders increase the probability that an offer will succeed.

Our analysis has also demonstrated that the tendency of target shareholders to participate in a tender offer is affected by the management's defensive strategies. Some defensive actions can actually raise the probability of the offer's success. These strategies may benefit shareholders. In addition, even defensive measures that could potentially cause the bid to be disallowed can benefit shareholders ex ante, by inducing bidders to make higher offers. Furthermore, there is a tendency for shareholders to raise their probabilities of tendering in response to managerial defensive actions in an offsetting manner, so that in some cases the defensive measure will not lead to any net reduction in the overall probability of an offer's success. Of course, defensive measures can also be designed to reduce the probability of an offer's success in ways that can reduce shareholder value.

The model suggests that a key determinant of the outcome of tender offers is whether target shareholders know as much as the bidder about the posttakeover value of the target's shares. If information is symmetric, then a bidder can always purchase as many shares as he seeks by bidding one cent above the posttakeover value in a tender offer. With asymmetric information, even the strategy of overbidding will not necessarily assure the success of the offer because target shareholders will interpret the higher bid as an indication that the 
posttakeover value of the shares is higher. This effect may be more apparent in the model presented in Appendix B in which the equilibrium bid is strictly lower with asymmetric than with symmetric information.

As shareholders become better informed about the size of the posttakeover value, the likelihood of a bid that is prone to failure (i.e., a bid far below the bidder's maximum improvement $\bar{z}$ ) becomes small. For bids in which a merger is expected or for management buy-outs, the posttakeover value of minority shares is often determined by a court decision about the fairness of the price. In this case, the bidder's information may be little better than that of target shareholders. Therefore, in the absence of management defensive actions and competing bids, we expect takeover bids for merger usually to succeed. On the other hand, in takeovers initiated to change the policy of the target without merger (e.g., Carl Icahn's takeover of Trans World Airlines), the bidder may have superior information about the prospects for increasing firm value. In such cases, failure of the bid becomes more likely. Our model suggests that future empirical studies should examine samples of these different kinds of takeovers separately.

Like most theoretical work on this topic, our model has assumed that the bidder is rational and profit maximizing. However, others (e.g., Roll 1986) have suggested that bidders may be afflicted with "hubris," systematically overestimating their ability to improve firm value. In our model, a bidder would have his bids accepted with certainty if target shareholders believed that he was overly confident and had a tendency to overbid. This suggests that "rational" bidders may have an incentive to develop and maintain reputations for hubris. Hence, in a repeated game, it may pay a rational bidder to overbid, to persuade future targets that he too is prone to hubris. ${ }^{30}$ This suggests that future empirical work should also try to analyze separately those bidders that make a number of bids.

\section{Appendix A}

Proof of Proposition 1

Parametrically differentiating (2) with respect to $z$ and solving for $d x / d z$ yields an expression that is strictly positive, by (3).

${ }^{30}$ See Kreps et al. (1982) for a reputation model in which rational players mimic irrational ones. Our argument for overbidding contrasts with the model of Leach (1988), in which merger bidders make low offers to gain the reputation for being tough bargainers. 


\section{Proof of Proposition 2}

Let us propose as off-equilibrium behavior by shareholders that if a bid of $\omega$ $>0.5-\alpha$ is made, then shareholders will still mix their actions to satisfy (5). Hence, regardless of $\omega$ the bid $x=z$ will satisfy the first-order condition (2). Direct calculation verifies that with the proposed probability schedule, the second-order condition for an interior global optimum (as well as the firstorder condition [2]) is satisfied by setting the bid $x=z$. At this bid, shareholders are indifferent between accepting and rejecting, which is consistent with randomization.

Only part 3 remains to be verified. Note that for a given $x, P(x ; \omega)$ is decreasing in $\omega$. Regardless of what value for $\omega$ is selected by the bidder, his optimal bid is $x=z$. Therefore, his profit on the shares he purchases is zero, and his entire gain is due to his gain on the original $\alpha$ shares. He maximizes expected wealth by choosing $\omega$ to maximize the probability of the offer's success. This occurs with the minimum value of $\omega$ consistent with obtaining control, $\omega=0.5-\alpha$.

\section{Appendix B}

\section{Unobserved Tendering Costs}

In this Appendix we provide a model in which shareholders possess a common cost of tendering that is unknown to the bidder. This is meant to describe, more explicitly, situations in which the bidder does not know perfectly the costs and benefits to the target shareholders of tendering. In this case, the success of the offer is determined by whether

$$
x>\hat{z}(x)+c,
$$

where $c$ is the cost of tendering, and $\hat{z}(x)$ is the shareholders' evaluation of $z$ given a bid of $x$. The bidder solves the same optimization problem as in the text, (1), and therefore has the same first-order condition with respect to his bid, (2). Each value of $z$ generates a corresponding optimal bid $x(z)$. Furthermore, in a perfectly revealing equilibrium, each value of $z$ corresponds to a different value of $x$, so that $z=\hat{z}(x)$. The probability of success is then the likelihood that $c$ falls in the range at which (B1) holds,

$$
P(x)=\int_{0}^{z-\hat{z}(x)} f(c) d c .
$$

Differentiating (B2) with respect to $x$ gives

$$
P^{\prime}(x)=f(x-\hat{z}(x))\left[1-\hat{z}^{\prime}(x)\right] .
$$

Substituting for $P^{\prime}(x)$ in (2) yields

$$
\omega \int_{0}^{z-\hat{z}(x)} f(c) d c=f(x-\hat{z}(x))\left[1-\hat{z}^{\prime}(x)\right](0.5 z-x \omega) .
$$

For an exogenously given distribution of $c$, this integral equation can be solved to give the equilibrium inverse bidding schedule $\hat{z}(x)$, which from (B2) also gives the probability of success schedule.

We shall develop our analysis under the assumption of a uniform distribu- 
tion for the tendering cost. We have shown that similar results can be obtained assuming a power density as well. ${ }^{31}$ Substituting the uniform density

$$
f(c)=\frac{1}{\bar{c}}, \quad c \in[0, \bar{c}],
$$

into (B4) and letting $\hat{z}(x)=z(x)$, the inverse of the bidding schedule $x(z)$, gives

$$
\omega(x-z)=\left[1-z^{\prime}(x)\right](0.5 z-x \omega) .
$$

\section{Symmetric Information Case}

A special case of interest is the one in which information about $z$ is symmetric (i.e., $z$ is known to all target shareholders). We refer to this as the "symmetric information" case, even though $c$ is still assumed unknown to the bidder. In this case, the inference schedule is $\hat{z}(x) \equiv z$ for all $x$ (equilibrium or not), so that $\hat{z}^{\prime}(x) \equiv 0$. Substituting into (B6) gives the symmetric information bidding function,

$$
x^{s}(z)=\left(\frac{0.5+\omega}{2 \omega}\right) z .
$$

Note that since $\omega<0.5$, this solution satisfies the fundamental property that $x^{s}>z$, so that (when the tendering cost is nonnegative) there is a positive probability of offer success.

\section{Asymmetric Information Case}

When $z$ is unknown to the target shareholders, the bidding schedule solves the differential equation (B6). Let $x^{a}$ denote the asymmetric information bid. A boundary condition that the equilibrium schedule must satisfy is that the highest-type bidder $\bar{z}$ must make a maximum bid $\bar{x}^{a}$ equal to $x^{s}(\bar{z})$ of the symmetric information case.

To see why, suppose that the maximum bid $\bar{x}^{a}>\bar{x}^{s}$. Then it would pay for the $\bar{z}$ type to reduce his bid to $\bar{x}^{s}$ because of two benefits. First, if he were viewed as type $\bar{z}$, then by revealed preference, since he preferred to bid $\bar{x}^{s}$ to $\bar{x}^{a}$ under symmetric information, he would still rather do so. Second, he may be viewed as a lower type, $z<\bar{z}$. If so, his gains from bidding $\bar{x}^{s}$ are even greater since his probability of success is greater.

Suppose, on the other hand, that $\bar{x}^{a}<\bar{x}^{s}$. Then it would pay for type $\bar{z}$ to raise his bid to $\bar{x}^{s}$, for essentially the same reasons as above. By revealed preference, if his type is still viewed as $\bar{z}$ since he chose $\bar{x}^{s}$ under symmetric information, he will still prefer it here. Second, if changing his bid were to lead to a lower inference of his type, his probability of success would rise and his gains would be even greater.

Having established this, we now show that the level of the bid under asymmetric information for any type below $\bar{z}$ is smaller than the bid under symmetric information. We may rewrite (B6) as

$$
x^{a}(z)=\left(\frac{0.5+\omega}{2 \omega}\right) z-z_{a}^{\prime}\left(\frac{0.5 z-\omega x^{a}}{2 \omega}\right),
$$

${ }^{31}$ A power density function for costs may be written as $f(c)=(1-\beta) \bar{c}^{-\beta-1} c^{-\beta}, \beta<1$. 
where $z_{a}^{\prime}$ is the derivative of the inference schedule with respect to $x$ under asymmetric information. Subtracting (B7) from (B8), we see that

$$
x^{a}-x^{s}=-z_{a}^{\prime}\left(\frac{0.5 z-\omega x^{a}}{2 \omega}\right) .
$$

In a separating equilibrium, by proposition $1, z_{a}^{\prime}>0$. The term in parentheses is proportional to the bidder's profit from winning, which must be positive. So $x^{a}<x^{s}$. It follows immediately from (B2) that in equilibrium a given type has a lower probability of success under asymmetric than under symmetric information, $P_{a}^{*}(z)<P_{s}^{*}(z)$.

Suppressing $a$ superscripts, we can solve the differential equation (B6) by the substitution $v \equiv z / x$, which gives a separable differential equation in $v$ and $x$. Imposing the appropriate boundary conditions gives the solution in implicit form of

$(x-z)^{(1-2 \omega) /(4 \omega-1)}(4 \omega x-z)^{-2 \omega /(4 \omega-1)}=(0.5-\omega)^{(1-2 \omega) /(4 \omega-1)}(2 \omega)^{-1 /(4 \omega-1)} \bar{z}^{-1}$

if $\omega \neq 1 / 4$ and

$$
2 e^{-3 / 2}(x-z)=\bar{z} e^{x / 2(x-z)}
$$

if $\omega=1 / 4$.

We have extended this model to include a managerial defensive action that imposes costs on the bidder prior to the outcome. In this case, the bidder's objective is

$$
\max _{x}(0.5 z-x \omega) P(x)-h(x)
$$

$h^{\prime}(x)<0$. Under the specific functional form $h(x)=k(x-\bar{x})^{2}, k>0$, we have verified a "compensation effect" similar to that described in the text. This is that the cost-imposing measure encourages higher bidding and hence raises the probability of offer success.

\section{References}

Bagnoli, Mark, and Lipman, Barton L. "Successful Takovers without Exclusion." Rev. Financial Studies 1 (Spring 1988): 89-110.

Banks, Jeffrey S., and Sobel, Joel. "Equilibrium Selection in Signaling Games." Econometrica 55 (May 1987): 647-64.

Bebchuk, Lucian A. "The Case for Facilitating Competing Tender Offers." Harvard Law Rev. 95 (March 1982): 1028-56.

Berkovitch, Elazar, and Khanna, Naveen. "A Theory of Acquisition Markets-Mergers vs. Tender Offers; Golden Parachutes and Greenmail." Manuscript. Ann Arbor: Univ. Michigan, 1988.

Bradley, Michael. "Interfirm Tender Offers and the Markets for Corporate Control.” J. Bus. 53 (October 1980): 345-76.

Bradley, Michael; Desai, Anand; and Kim, E. Han. "The Rationale behind Interfirm Tender Offers: Information or Synergy?" J. Financial Econ. 11 (April 1983): 183-206.

Cho, In-Koo, and Kreps, David M. "Signaling Games and Stable Equilibria." Q.J.E. 102 (May 1987): 179-221. 
Dann, Larry Y., and DeAngelo, Harry. "Corporate Financial Policy and Corporate Control: A Study of Defensive Adjustments in Asset and Ownership Structure." J. Financial Econ. 20 (January/March 1988): 87-127.

Easterbrook, Frank H., and Fischel, Daniel R. "The Proper Role of a Target's Management in Responding to a Tender Offer." Harvard Law Rev. 94 (April 1981): 1161-1204.

Fishman, Michael J. "A Theory of Pre-emptive Takeover Bidding." Rand J. Econ. 19 (Spring 1988): 88-101.

Franks, Julian, and Harris, Robert. "Shareholder Wealth Effects of Corporate Takeovers: The U.K. Experience, 1955-85." Manuscript. London: London Bus. School, 1988.

Giammarino, Ronald M., and Heinkel, Robert L. "A Model of Dynamic Takeover Behavior." J. Finance 41 (June 1986): 465-80.

Giammarino, Ronald M., and Lewis, Tracy. "A Theory of Negotiated Equity Financing." Rev. Financial Studies 1 (Fall 1988): 265-88.

Gilson, Ronald J. "A Structural Approach to Corporations: The Case against Defensive Tactics in Tender Offers.” Stanford Law Rev. 33 (May 1981): 819-91.

Grossman, Sanford J., and Hart, Oliver D. "Takeover Bids, the Free-Rider Problem, and the Theory of the Corporation." Bell J. Econ. 11 (Spring 1980): 42-64.

Grossman, Sanford J., and Perry, Motty. "Perfect Sequential Equilibrium.”J. Econ. Theory 39 (June 1986): 97-119.

Harsanyi, John C. "Games with Randomly Disturbed Payoffs: A New Rationale for Mixed-Strategy Equilibrium Points." Internat. J. Game Theory 2, no. 1 (1973): 1-23.

Hirshleifer, David, and Png, I. P. L. "The Information Conveyed by a Tender Offer and the Takeover Price of a Target Firm." Rev. Financial Studies 2, no. 4 (1990).

Jarrell, Gregg A. "The Wealth Effects of Litigation by Targets: Do Interests Diverge in a Merge?" J. Law and Econ. 28 (April 1985): 151-77.

Jarrell, Gregg A., and Bradley, Michael. "The Economic Effects of Federal and State Regulations of Cash Tender Offers." J. Law and Econ. 23 (October 1980): 371-407.

Jarrell, Gregg A., and Poulsen, Annette. "Shark Repellents and Stock Prices: The Effects of Antitakeover Amendments since 1980.” J. Financial Econ. 19 (September 1987): 127-68.

Judd, Kenneth L. "The Law of Large Numbers with a Continuum of IID Random Variables." J. Econ. Theory 35 (February 1985): 19-25.

Leach, J. Chris. "Repetition, Reputation, and Raiding." Manuscript. Ithaca, N.Y.: Cornell Univ., 1988.

Kreps, David M.; Milgrom, Paul; Roberts, John; and Wilson, Robert. "Rational Cooperation in the Finitely Repeated Prisoners' Dilemma." J. Econ. Theory 27 (August 1982): 245-52.

Malatesta, Paul H., and Thompson, Rex. "Government Regulation of the Corporate Acquisitions Market: The Williams Act.” Manuscript. Seattle: Univ. Washington, 1988.

Malatesta, Paul H., and Walkling, Ralph A. "Poison Pill Securities: Stockholder Wealth, Profitability, and Ownership Structure."J. Financial Econ. 20 (January/March 1988): 347-76.

Morck, Randall; Shleifer, Andrei; and Vishny, Robert W. "Characteristics of 
Targets of Hostile and Friendly Takeovers." In Corporate Takeovers: Causes and Consequences, edited by Alan J. Auerbach. Chicago: Univ. Chicago Press (for NBER), 1988.

Poulsen, Annette, and Jarrell, Gregg A. "Stock Trading before the Announcement of Tender Offers: Insider Trading or Market Anticipation." Washington: Securities and Exchange Comm., 1986.

Roll, Richard. "The Hubris Hypothesis of Corporate Takeovers." J. Bus. 59, no. 2, pt. 1 (April 1986): 197-216.

Ruback, Richard S. "Do Target Shareholders Lose in Unsuccessful Control Contests?" In Corporate Takeovers: Causes and Consequences, edited by Alan J. Auerbach. Chicago: Univ. Chicago Press (for NBER), 1988.

Ryngaert, Michael. "The Effect of Poison Pill Securities on Shareholder Wealth."J. Financial Econ. 20 (January/March 1988): 377-417.

Samuelson, William, and Rosenthal, Leonard. "Price Movements as Indicators of Tender Offer Success." J. Finance 41 (June 1986): 481-99.

Shleifer, Andrei, and Vishny, Robert W. "Large Shareholders and Corporate Control." J.P.E. 94, no. 3, pt. 1 (June 1986): 461-88.

Walkling, Ralph A. "Predicting Tender Offer Success: A Logistic Analysis." J. Financial and Quantitative Analysis 20 (December 1985): 461-78.

Walkling, Ralph A., and Edmister, Robert O. "Determinants of Tender Offer Premiums." Financial Analysts J. 41 (January-February 1985): 27-37. 